\title{
Degradation Behaviors of Thai Bombyx mori Silk Fibroins Exposure to Protease Enzymes
}

\author{
Chuleerat Wongnarat, Prasong Srihanam* \\ Department of Chemistry and Center of Excellence for Innovation in Chemistry, \\ Faculty of Science, Mahasarakham University, Maha Sarakham, Thailand \\ Email: *prasong.s@msu.ac.th
}

Received November 11, 2012; revised December 11, 2012; accepted December 20, 2012

\begin{abstract}
The degradation behaviors of Thai Bombyx mori called Samrong and Nanglai silk fibroins exposure to protease enzymes; protease XIV, protease XXIII and $\alpha$-chymotrypsin type II were studied in this work. The degradation behaviors were expressed by their weight loss, morphological and secondary structure changes as well as thermal properties. Samrong showed higher percentage of weight loss than Nanglai. SEM micrographs indicated that silk fibroin were destroyed and showed many holes on their fiber surfaces. All of silk samples were increasable destroyed when exposure to the protease enzyme for long incubation period. With thermal analysis, both silk fibroin presented the thermal stability in the same profile. The result suggested that the selected silk fibroin should be composed of similar pattern of amino acids and their ratios. However, the protease susceptibility of each silk fibroin slightly varied in case of morphology observation. This might be affected by their genetic variety.
\end{abstract}

Keywords: Degradation; Enzyme; Protease; Samrong; Nanglai

\section{Introduction}

Recently, various biomaterials have been explored for applications [1,2]. Various ideal characteristics including non-immunogenic, biocompatible, biodegradable and high mechanical strength are main criterions for decision use [3]. Most biodegradable polymers such as collagen, gelatin, chitosan and polyester synthetics have been shown to developing tissue, but most are insufficient in mechanical properties [4,5]. However, their physical and chemical properties can be easily modified to achieve desirable mechanical and degradation characteristics [3].

Silk is a fibrous protein produced by a variety of insects [6], especially silkworm. Silkworm was divided into 2 groups i.e., mulberry or domesticated silkworm (as well known Bombyx mori) and non-mulberry or wild silkmoth [7]. Bombyx mori (B. mori) have been widely used in the textile industry for thousands of years. In the non-textile field, $B$. mori silk fibroin has been extensively characterized and used commercially for biomedical sutures and as cosmetic and food additives for decades $[8,9]$. There are few reports on the application of wild silk fibroin. However, some wild silkmoth: Tasar (Antheraea pernyi and Antheraea mylitta), Muga (Antheraea assamensis) and Eri (Samia ricini) are wildly cultured and have been gradually applied for many fields

\footnotetext{
"Corresponding author.
}

[10]. The degradation rate of silk may be highly variable depending on its structural and morphological features as well as characteristics of the biological environment.

Previous literatures have been investigated the degradation behaviors of silk fibroins exposed to different proteolytic enzymes such as protease XIV [11], $\alpha$-chymotrypsin [12], protease XXI [13]. Separately protease including protease XIV, protease XXIII and $\alpha$-chymotrypsin type II were chosen as model enzymes. Some characteristics were examined to contribute findings of their enzyme effects including morphology, weight loss, and thermal properties.

\section{Experimental}

\subsection{Material}

Thai Bombyx mori silk cocoon of 2 varieties (Nanglai and Samrong) were kindly supplied from Silk Innovation Center (SIC), Mahasarakham University, Thailand.

\subsection{Preparation of Silk Fibroin}

Domesticated silk; B. mori (locally called "Nang lai" and "Samrong") silk cocoons were used for preparation of silk fiber and subjected as materials in this study. The cocoons were firstly boiled in $0.5 \%(\mathrm{w} / \mathrm{v}) \mathrm{Na}_{2} \mathrm{CO}_{3}$ solution at $90^{\circ} \mathrm{C}$ for excluding sericin to obtain silk fibroin (SF). After degumming in each step, silk fiber was 
washed with distilled water.

\subsection{In Vitro Degradation of Silk Fibroin}

Degradation of SF by action of the protease enzymes: $\alpha$-chymotrypsin II, protease XIV and protease XXIII were investigated as previously reported [14]. Briefly, each enzyme was prepared by dissolving in phosphate buffer saline (PBS) to give 1 unit of enzyme activity. The $\mathrm{SF}$ was incubated in enzyme solution at $37^{\circ} \mathrm{C}$ for 49 days. Contrast SF immersed in PBS without enzyme was used as a control. The enzyme solution was changed every 7 days and replaced at the same volume of fresh enzyme solution. The SF after different periods of degradation was shown as percentage of weight loss using followed equation;

$$
\text { Weight loss }(\%)=\frac{W i-W f}{W i} \times 100
$$

where $W i$ is initial weight of sample while $W f$ is the weight of sample after immersing in enzyme solution.

\subsection{Characterization}

\subsubsection{Morphological Observation}

Samples were dehydrated and segmented $(\sim 1 \mathrm{~cm}$ in length), then mounted on the stub with double-sided carbon tapes. Yarns were sputter-coated with gold for enhanced surface conductivity. Current and voltage were adjusted to give power of $2 \mathrm{~W}(3 \mathrm{~mA}, 15 \mathrm{kV})$ for $3 \mathrm{~min}$. The samples were examined using scanning electron microscope (SEM) (JEOL-JSM 6460LV).

\subsubsection{Thermal Behaviors Analysis}

A TA-Instruments TG SDT Q600 (Leken's drive, New Castle, DE) thermogravimetric analyzer was be used to determine the thermal decomposition patterns of the SF. Samples were loaded in platinum crucible. The analysis condition would be $50^{\circ} \mathrm{C}-800^{\circ} \mathrm{C}$ at heating rate of $20^{\circ} \mathrm{C}$ $/ \mathrm{min}$ under nitrogen atmosphere. The TGA data were recorded online in TA instrument's Q series explorer software. The analyses of the TG data would be done using TA Instrument's Universal Analysis 2000 software (version 3.3B).

\section{Results and Discussion}

\subsection{Weight Loss of SF}

The weight losses of SF after incubation with protease enzymes are shown in Figures 1-3. The SF of Samrong showed dominantly higher weight loss than Nanglai after exposure to protease XIV. The weight loss of the Samrong SF gradually increased from the initial day up to the end of incubation for 49 days at about $27.5 \%$. Nanglai SF was stable of its weight in protease XIV until 14 days,

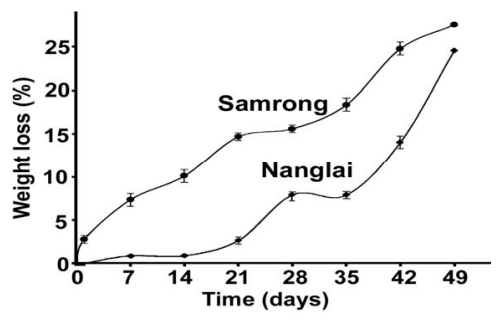

Figure 1. Weight loss of SF incubated with protease XIV.

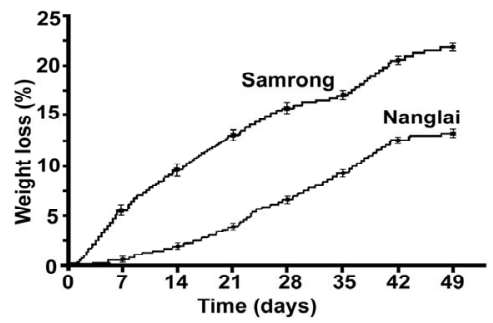

Figure 2. Weight loss of SF after incubation with protease XXIII.

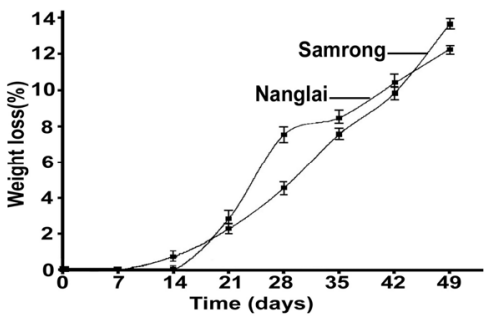

Figure 3. Weight loss of SF after incubation with $\alpha$-chymotrypsin type II.

and then slightly increased at about $7.5 \%$ of weight loss after exposure to enzyme for 35 days. The degradation of Nanglai SF was dramatically increased when the incubation time over the 35 days until the end at about $25 \%$ of weight loss.

Exposure to protease XXIII, Samrong SF degraded at first day of incubation and showed exponential pattern up to 49 days. The weight loss of Samrong SF by protease XXIII was about $17.5 \%$. Nanglai SF started to degrade from initial day until 35 days of investigation. Incubation SF with $\alpha$-chymotrysin type II, both of SF was found after incubation for 14 days. The effect of this enzyme on SF showed different profiles compared to protease XIV and protease XXIII. Nanglai SF degraded in the highest at 28 days and prolonged until 42 days of incubation time. Samrong showed the highest of weight loss at 35 days. At the end of degradation, Samrong has the highest weight loss at about $13.6 \%$ whereas Nanglai about $12.3 \%$.

The results showed that the extent weight loss depending on the type of enzyme, silk variety and on the treatment time. However, the actions of each enzyme on different types of SF were varied. It can be concluded 
that all of enzyme can be degraded SF of B. mori, but with different characteristics. The amount and accessibility of the sites of proteolysis have probably acted as important factor in examining of SF degradation [12]. Previous reports confirmed that different degradation behavior of SF was influenced by substrate structure and morphology, smoothness surface, close packing of fibroin chains and fibrous structure orientation $[15,16]$. Moreover, the degradation behavior of SF was also varied from different preparation process [17].

\subsection{Morphological Study}

In general, all of SF can be destroyed by protease XIV, especially in their surfaces. SF of Samrong showed higher susceptibility to the protease XIV than Nanglai silk. The results indicated that Samrong SF started degrade at the 14 days of incubation (Figure 4), while Nanglai SF was found after incubation for 28 days (Figure 5). The degradation of surfaces was dominantly occurred when the incubation time increased. However, the effect of the protease XIV enzyme on SF of each silk variety was varied which can be observed from the area of surfaces degradation. The effect of protease XXIII on SF of Samrong variety was found higher than that of Nanglai variety. The surfaces of Samrong SF occurs the destruction trace at 14 days of incubation (Figure 6), while Nanglai SF was 21 days (Figure 7). Moreover,
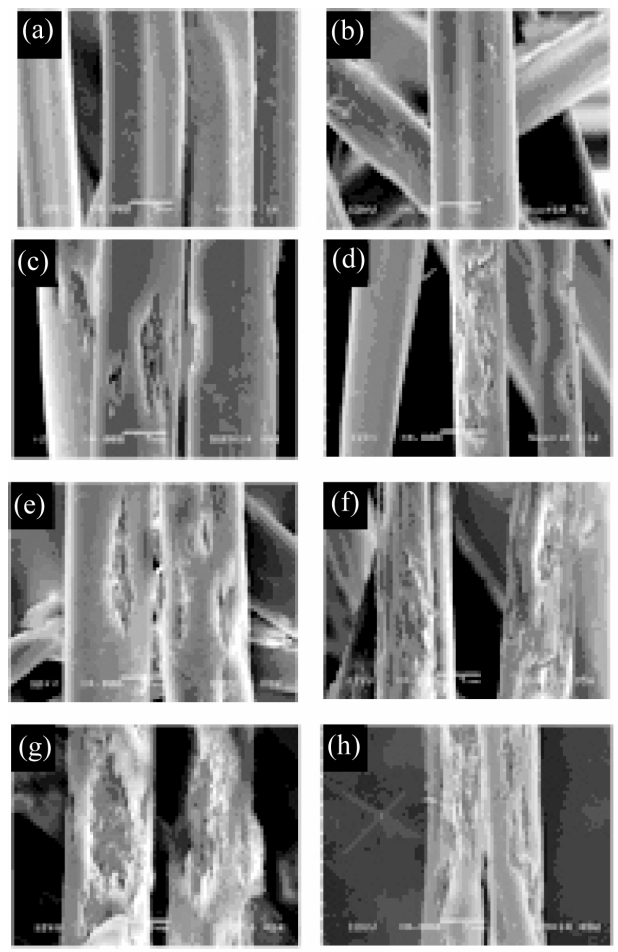

Figure 4. SEM images of Thai $B$. mori (Samrong) SF incubated with protease XIV for 1 (a); 7 (b); 14 (c); 21 (d); 28 (e); 35 (f); 42 (g) and 49 (h) days. All bars $=5 \mu \mathrm{m}$.
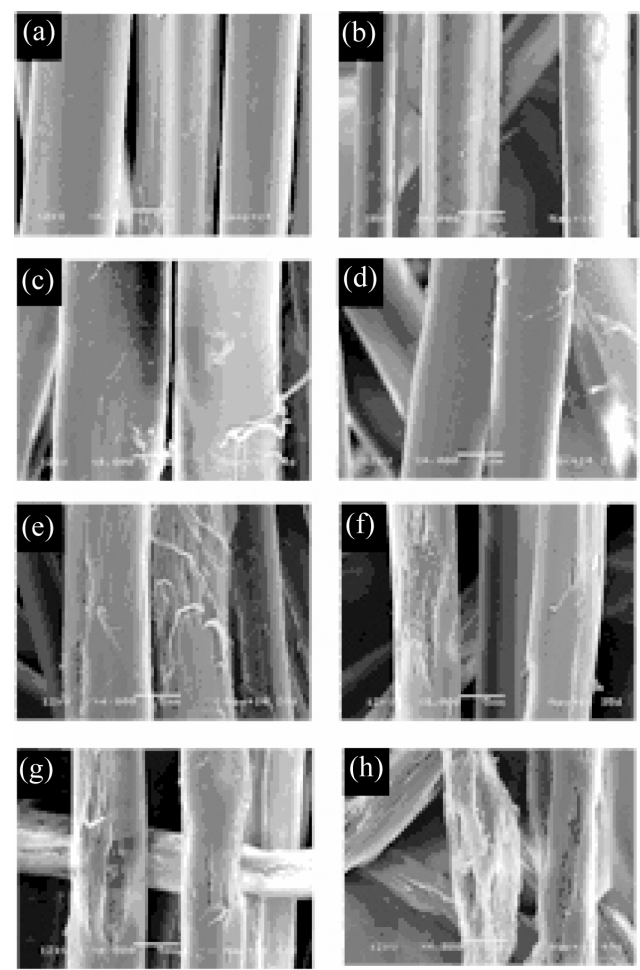

Figure 5. SEM images of Thai $B$. mori (Nanglai) SF incubated with protease XIV for 1 (a); 7 (b); 14 (c); 21 (d); 28 (e); 35 (f); 42 (g) and 49 (h) days. All bars $=5 \mu \mathrm{m}$.
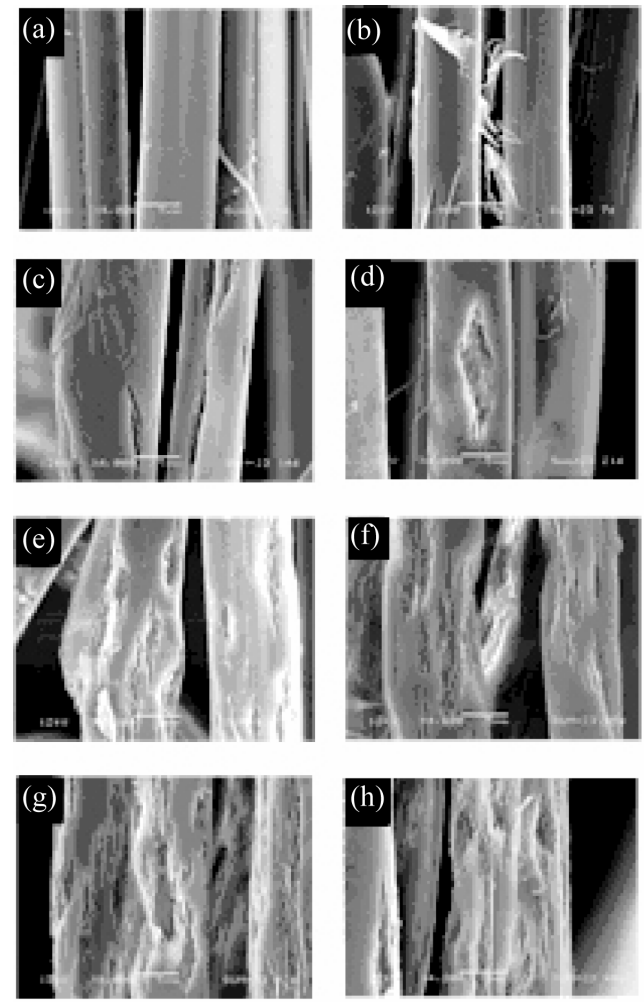

Figure 6. SEM images of Thai $B$. mori (Samrong variety) SF incubated with protease XXIII for 1 (a); 7 (b); 14 (c); 21 (d); 28 (e); 35 (f); 42 (g) and 49 (h) days. All bars $=5 \mu \mathrm{m}$. 

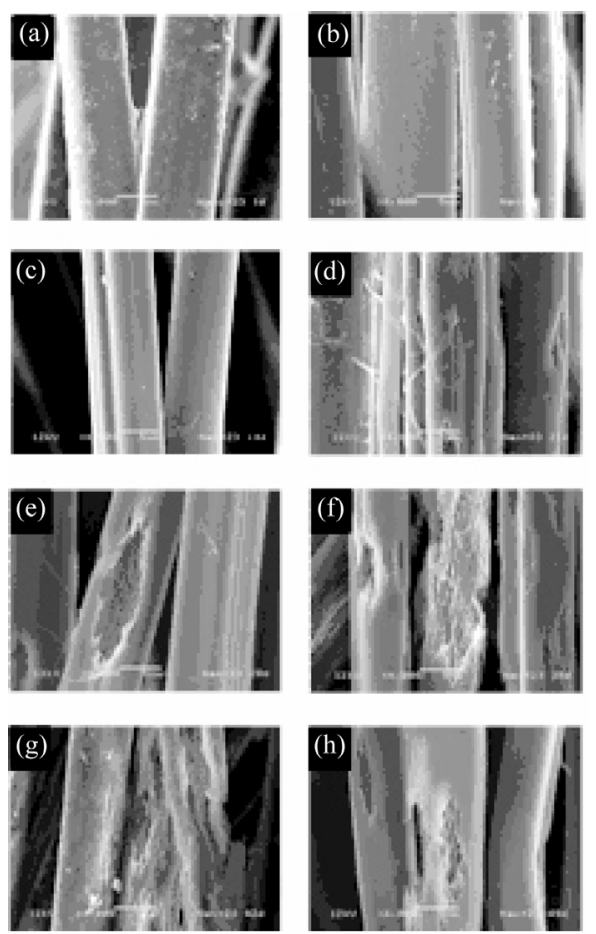

Figure 7. SEM images of Thai B. mori (Nanglai) SF incubated with protease XXIII for 1 (a); 7 (b); 14 (c); 21 (d); 28 (e); 35 (f); 42 (g) and 49 (h) days. All bars $=5 \mu \mathrm{m}$.

Samrong SF showed higher surface erosion than that of Nanglai SF at the same incubation time. The action of $\alpha$-chymotrysin type II on SF degradation was similar profile with protease XXIII. It can be degraded SF both of domesticated silks. Samrong SF was destroyed by this enzyme more than Nanglai SF. The erosion of Nanglai SF surfaces was observed after exposure to enzyme for 21 days (Figure 8), as same as the SF of Samrong (Figure 9). However, Samrong SF appeared the breaking of SF surfaces in higher than Nanglai at the end of incubation time. Generally, the degradation pattern was similar to protease XXIII since the destruction was along with silk fibers. The protease demonstrated to cleave silk at multiple locations [11]. The SEM micrographs showed that increased fragmentation of fibroin overtime in the protease-digested was observed. The fibroin was degraded via a surface erosion process. The increase in exposed surface area on fractured sites provided additional area for enzymatic attack on silk, but not to the rest of the fibroin. In this work, some cracks and holes occurred on the SF with the size of hole increased as a function of exposure period. However, the holes were varied depending on silk variety and types of protease enzyme used. In general, the cracks and holes of SF were probably due to the degradation in the amorphous regions [17]. The crystal sizes are important elements for mechanical properties and degradation rates of polymers [18].
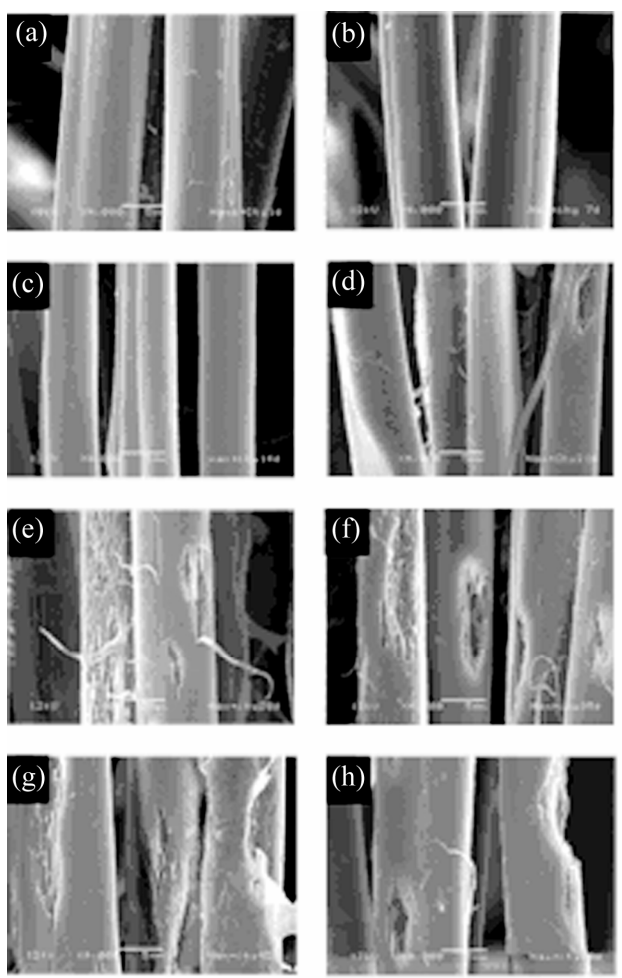

Figure 8. SEM images of Thai $B$. mori (Nanglai) SF incubated with chymotrypsin for 1 (a); 7 (b); 14 (c); 21 (d); 28 (e); 35 (f); 42 (g) and 49 (h) days. All bars $=5 \mu \mathrm{m}$.
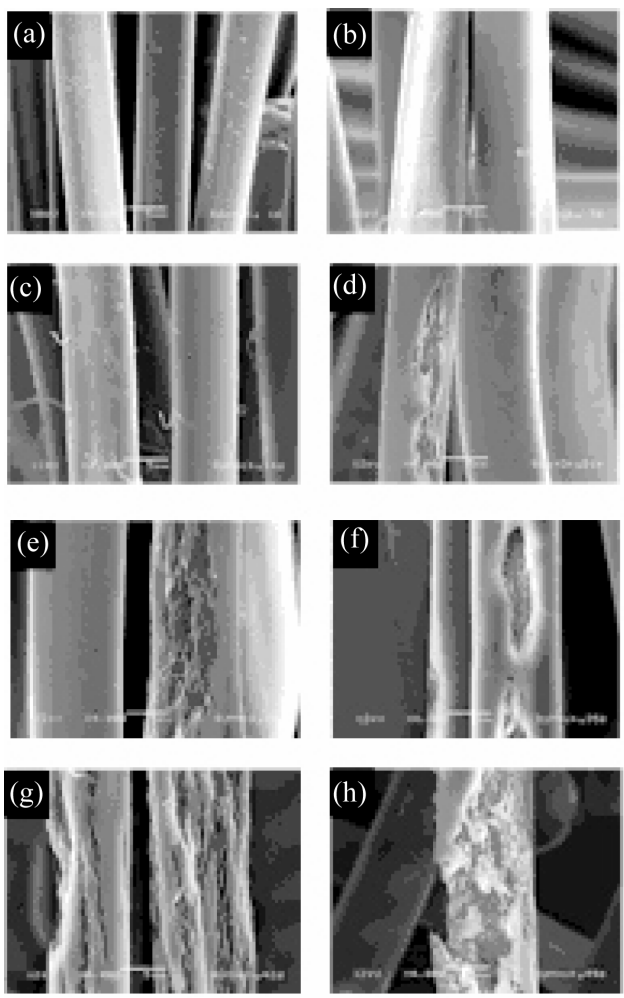

Figure 9. SEM images of Thai $B$. mori (Somrong) SF incubated with chymotrypsin for 1 (a); 7 (b); 14 (c); 21 (d); 28 (e); 35 (f); 42 (g) and 49 (h) days. All bars $=5 \mu \mathrm{m}$. 


\subsection{Thermal Properties}

Since protease XIV showed the highest degradation effect on SF. Therefore it is chosen enzyme model to study thermal stability of SF after immersing in enzyme solution. With protease XIV, Samrong SF (Figure 10) showed heat flow curves quite different pattern compared to Nanglai silk (Figure 11). Both of domesticated silks, they showed sharply one peak of maximum decomposition rate at about $325^{\circ} \mathrm{C}$ with a minor peak at $420^{\circ} \mathrm{C}$. In addition, the peaks at below $100^{\circ} \mathrm{C}$ were also observed in both of silk varieties. The endothermic peaks of each SF were slightly decreased when the incubation time increased. Considering from heat flow curves, slightly differences in patterns were observed, especially on initial day until 14 days of study. Nanglai SF showed single pattern of heat flow throughout the study, but Samrong SF occurred 2 forms of heat flow curves. The first was observed at initial day to 14 days of incubation to enzyme and second pattern was found after 14 days of study.

The poly(Ala) $)_{\mathrm{n}}$ sequences are expected to be location

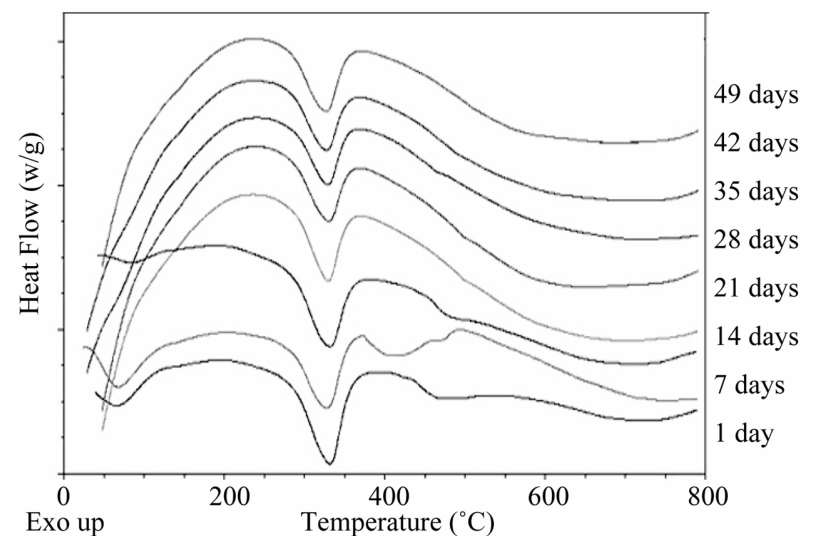

Figure 10. Heat flow curves of Samrong SF incubated with protease XIV.

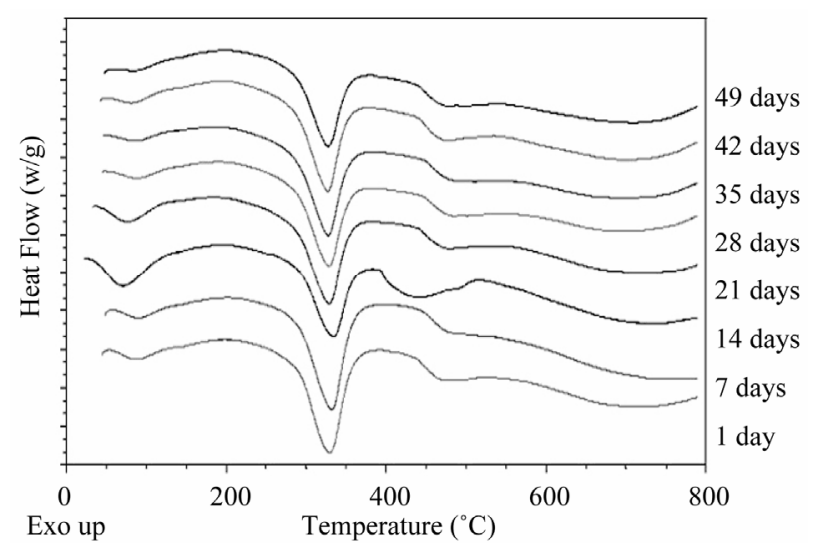

Figure 11. Heat flow curves of Nanglai SF incubated with protease XIV. for $\beta$-sheet and $\alpha$-helix structures, whereas all Gly residues were reported to take random coil conformation; nearly all tyrosine residues [13]. Among the enzymes, protease XIV showed strong effect on the SF degradation than others which can observe from many points of the $\mathrm{T}_{d \text {,max }}$. The SF slight to decrease their thermal stability after incubation with protease in long periods. This might be suggested that the crystalline regions of SF was destroyed by protease and resulted to loose of their strength.

\section{Conclusion}

The effects of some proteases; protease XIV, protease XXIII and $\alpha$-chymotrypsin enzyme on degradation of Thai $B$. mori SF were reported in this study. The obtained results from percentage of weight loss, SEM micrographs, and thermal study found that all protease enzymes can be destroyed the surfaces of SF. The ability of each enzyme on SF degradation was varied. However, thermal property of SF was affected by proteases since they destroyed SF surface and resulted to decrease silk stability.

\section{Acknowledgements}

The authors would like to thank Division of Research Facilitation and Dissemination, Graduate School, Department of Chemistry, Faculty of Science, Mahasarakham University and the Center of Excellence for Innovation in Chemistry (PERCH-CIC), Commission on Higher Education, Ministry of Education, Thailand for financial support of this work.

\section{REFERENCES}

[1] D. N. Bikiaris, G. Z. Papageorgiou, D. S. Achilias, E. Pavlidou and A. Stergiou, "Miscibility and Enzymaticdegradation Studies of Poly(epsilon-caprolactone)/Poly(propylene succinate) Blends," European Polymer Journal, Vol. 43, No. 6, 2007, pp. 2491-2503. doi:10.1016/j.eurpolymj.2007.03.051

[2] Z. Liu, Y. Jiao, Y. Wang, C. Zhou and Z. Zhang, "Polysaccharides-Based Nanoparticles as Drug Delivery Systems," Advanced Drug Delivery Reviews, Vol. 60, No. 15, 2008, pp. 1650-1662. doi:10.1016/j.addr.2008.09.001

[3] Y. Cao and B. Wang, "Biodegradation of Silk Biomaterials,” International Journal of Molecular Sciences, Vol. 10, No. 4, 2009, pp. 1514-1524. doi:10.3390/ijms10041514

[4] L. Dürselen, M. Dauner, H. Hierlemann, H. Planck, L. E. Claes and A. Ignatius, "Resorbable Polymer Fibers for Ligament Augmentation,” Journal of Biomedical Materials Research, Vol. 58, No. 6, 2001, pp. 666-672.

[5] L. Lu, S. J. Peter, M. D. Lyman, H. L. Lai, S. M. Leite, J. A. Tamada, S. Uyama, J. P. Vacanti, R. Langer and A. G. Mikos, "In Vitro and in Vivo Degradation of Porous 
Poly(DL-lactic-co-glycolic acid) Foams,” Biomaterials, Vol. 21, No. 18, 2000, pp. 1837-1845. doi:10.1016/S0142-9612(00)00047-8

[6] G. H. Altman, F. Diaz, C. Jakuba, T. Calabro, R. L. Horan, J. Chen, H. H. Lu, J. Richmond and D. L. Kaplan, “Silk-Based Biomaterials," Biomaterials, Vol. 24, No. 3, 2003, pp. 401-416.

[7] S. Q. Yan, C. X. Zhao, X. F. Wu, Q. Zhang and M. Z. Li, "Gelation Behavior of Antheraea pernyi Silk Fibroin," Science China Chemistry, Vol. 53, No. 3, 2009, pp. 535541. doi:10.1007/s11426-010-0093-0

[8] M. Z. Li, Z. Y. Wu, C. S. Zhang, S. Z. Lu, H. J. Yan, D. Huang and H. L. Ye, "Study on Porous Silk Fibroin Materials. II. Preparation and Characteristics of Spongy Porous Silk Fibroin Materials," Journal of Applied Polymer Science, Vol. 79, No. 12, 2001, pp. 2192-2199.

[9] C. Vepari and D. L. Kaplan, "Silk as a Biomaterial,” Progress in Polymer Science, Vol. 32, No. 8-9, 2007, pp. 991-1007. doi:10.1016/j.progpolymsci.2007.05.013

[10] J. Kundu, M. Dewan, S. Ghoshal and S. C. Kundu, "Mulberry Non-Engineered Silk Gland Protein vis-à-vis Silk Cocoon Protein Engineered by Silkworms as Biomaterial Matrices," Journal of Materials Science Materials in Medicine, Vol. 19, No. 7, 2008, pp. 2679-2689. doi:10.1007/s10856-008-3398-1

[11] R. L. Horan, K. Antle, A. L. Collette, Y. Z. Huang, J. Huang, J. E. Moreau, V. Volloch, D. L. Kaplan and G. H. Altman, “In Vitro Degradation of Silk Fibroin,” Biomaterials, Vol. 26, No. 17, 2005, pp. 3385-3393. doi:10.1016/j.biomaterials.2004.09.020

[12] T. Arai, G. Freddi, R. Innocenti and M. Tsukada, "Biodegradation of Bombyx mori Silk Fibroin Fibers and
Films,” Journal of Applied Polymer Science, Vol. 91, No. 4, 2004, pp. 2383-2390. doi:10.1002/app.13393

[13] P. Taddei, T. Arai, A. Boschi, P. Monti, M. Tsukada and G. Freddi, "In Vitro Study of the Proteolytic Degradation of Antheraea pernyi Silk Fibroin,” Biomacromolecules, Vol. 7, No. 1, 2006, pp. 259-267. doi:10.1021/bm0506290

[14] Z. She, B. Zhang, C. Jin, Q. Feng and Y. Xu, "Preparation and in Vitro Degradation of Porous Three-Dimensional Silk Fibroin/Chitosan Scaffold,” Polymer Degradation and Stability, Vol. 93, No. 7, 2008, pp. 1316-1322. doi:10.1016/j.polymdegradstab.2008.04.001

[15] M. Tsukada, G. Freddi, M. Nagura, H. Ishikawa and N. Kasai, "Structural Changes of Silk Fibers Induced by Heat Treatment," Journal of Applied Polymer Science, Vol. 46, No. 11, 1992, pp. 1945-1953. doi:10.1002/app.1992.070461107

[16] H. Y. Kweon, J. H. Yeo, K. G. Lee, H. C. Lee, H. S. Na, Y. H. Won and C. H. Cho, "Semi Interpenetrating Polymer Networks Composed of Silk Fibroin and Poly(ethylene glycol) for Wound Dressing," Biomedical Materials, Vol. 3, No. 3, 2008, pp. 1-5. doi:10.1088/1748-6041/3/3/034115

[17] J. Zhou, C. Cao, X. Ma, L. Hu, L. Chen and C. Wang, “In Vitro and in Vivo Degradation Behavior of Aqueous-Derived Electrospun Silk Fibroin Scaffolds,” Polymer Degradation and Stability, Vol. 95, No. 9, 2010, pp. 16791685. doi:10.1016/j.polymdegradstab.2010.05.025

[18] K. Numata, P. Cebe and D. L. Kaplan, "Mechanism of Enzymatic Degradation of Beta-Sheet Crystals," Biomaterials, Vol. 31, No. 10, 2010, pp. 2926-2933. doi:10.1016/i.biomaterials.2009.12.026 